\title{
Discovery and characterization of Acanthamoeba castellanii mitochondrial 5S rRNA
}

\author{
CHARLES E. BULLERWELL, MURRAY N. SCHNARE, and MICHAEL W. GRAY \\ Canadian Institute for Advanced Research, Program in Evolutionary Biology, Department of Biochemistry and Molecular Biology, Dalhousie \\ University, Halifax, Nova Scotia B3H 1X5, Canada
}

\begin{abstract}
Although 5S rRNA is a highly conserved and universal component of eubacterial, archaeal, chloroplast, and eukaryotic cytoplasmic ribosomes, a mitochondrial DNA-encoded 5S rRNA has so far been identified only in land plants and certain protists. This raises the question of whether 5S rRNA is actually required for and used in mitochondrial translation. In the protist Acanthamoeba castellanii, BLAST searches fail to reveal a 5S rRNA gene in the complete mitochondrial genome sequence, nor is a 5S-sized RNA species detectable in ethidium bromide-stained gels of highly purified mitochondrial RNA preparations. Here we show that an alternative visualization technique, UV shadowing, readily detects a novel, mitochondrion-specific small RNA in A. castellanii mitochondrial RNA preparations, and that this RNA species is, in fact, a 5S rRNA encoded by the A. castellanii mitochondrial genome. These results emphasize the need for caution when interpreting negative results that suggest the absence of 5S rRNA and/or a mitochondrial DNA-encoded 5S rRNA sequence in other (particularly protist) mitochondrial systems.
\end{abstract}

Keywords: Protist; mtDNA; ribosome

\section{INTRODUCTION}

5S rRNA is a highly conserved and universal component of eubacterial, archaeal, plastid, and eukaryotic cytoplasmic ribosomes. This small $(\sim 120 \mathrm{nt})$ structured RNA interacts with ribosomal proteins (L5 in eukaryotes; L5, L18, and L25 in bacteria and organelles), and the resulting RNA-protein complex is found in the large ribosomal subunit (Moore 1996). Despite the fact that $5 S$ rRNA was discovered some 40 years ago (Rosset and Monier 1963), its function is still not precisely defined; what is known is that the $5 \mathrm{~S}$ ribonucleoprotein complex contributes importantly, albeit indirectly, to many of the functions of large ribosomal subunits that contain it (Moore 1996).

Surprisingly, in view of its otherwise ubiquitous distribution, 5S rRNA appears not to be universally present in mitochondrial systems. Plant mitochondrial ribosomes do contain a distinctive 5S rRNA species (Cunningham et al. 1976; Leaver and Harmey 1976; Spencer et al. 1981), encoded by the mitochondrial genome (Bonen and Gray 1980; Oda et al. 1992; Unseld et al. 1997; Kubo et al. 2000). A

Reprint requests to: Michael W. Gray, Canadian Institute for Advanced Research, Program in Evolutionary Biology, Department of Biochemistry and Molecular Biology, Dalhousie University, Halifax, Nova Scotia B3H 1X5, Canada; e-mail: m.w.gray@dal.ca.

Article and publication are at http://www.rnajournal.org/cgi/doi/ 10.1261/rna.2170803. recognizable 5S rRNA gene is also present in some protist mitochondrial genomes, notably those of certain green, red, and brown algae (Wolff et al. 1994; Ohta et al. 1998; Burger et al. 1999; Turmel et al. 1999, 2002a, 2000b; Oudot-Le Secq et al. 2001, 2002) and jakobid flagellates (Lang et al. 1996, 1999). However, an obvious 5S rRNA gene has not been identified in other protist mtDNAs (Gray et al. 1998), or in any of the more than 100 animal mitochondrial genomes completely sequenced to date. Nor has a $5 \mathrm{~S}$ rRNA species been detected in isolated animal mitochondrial ribosomes (O'Brien and Denslow 1996). By the same token, fungal mitochondrial systems evidently lack a 5S rRNA component (Lizardi and Luck 1971), although the possibility of preparative loss of $5 \mathrm{~S}$ rRNA during isolation of fungal mitochondrial ribosomes has been debated (Datema et al. 1974; Michel et al. 1977).

A number of explanations could account for the absence of 5S rRNA in any given mitochondrial translation system. For example, the functional role of $5 \mathrm{~S}$ rRNA may simply be dispensable in some cases. Other possibilities are that the functional role of $5 \mathrm{~S}$ rRNA has been assumed by other ribosomal components (ribosomal proteins?) or that a $5 \mathrm{~S}$ equivalent sequence is covalently imbedded in the sequence of the large subunit rRNA (Nierlich 1982; Thurlow et al. 1984). There is no evidence to support the former suggestion, whereas the latter can be discounted by comparative analysis of rRNA secondary structure (Lang et al. 1987; 
Gutell et al. 1993). A fourth possibility is that the function of $5 \mathrm{~S}$ rRNA has been assumed in mitochondria by an extramitochondrial 5S rRNA species imported into mitochondria. In this regard, intriguing recent evidence suggests that nucleus-encoded (cytoplasmic) 5S rRNA is a bona fide intramitochondrial component in animals (Yoshionari et al. 1994; Magalhães et al. 1998), and that human mitochondria are able to import 5S rRNA (Entelis et al. 2001).

On the other hand, a mitochondrial 5S rRNA species may be present but be too divergent in sequence and higherorder structure to be readily recognized as such. We present here one such case-in the amoeboid protist, Acanthamoeba castellanii — where previous approaches, both computational and experimental, were unable to detect either a $5 \mathrm{~S}$ rRNA gene in the completely sequenced mitochondrial DNA or a mitochondrion-specific 5S rRNA.

\section{RESULTS AND DISCUSSION}

When A. castellanii RNA fractions were resolved by polyacrylamide gel electrophoresis, UV shadowing (Hassur and Whitlock 1974) revealed the presence of a novel, highly abundant, small RNA species (X) in purified mitochondrial (but not cytoplasmic) RNA (Fig. 1A). Species X was, however, invisible when gels were stained with ethidium bromide (Fig. 1B), an intercalating agent whose interaction with nucleic acids is strongly affected by the degree and stability of base pairing. Detection and isolation of species X

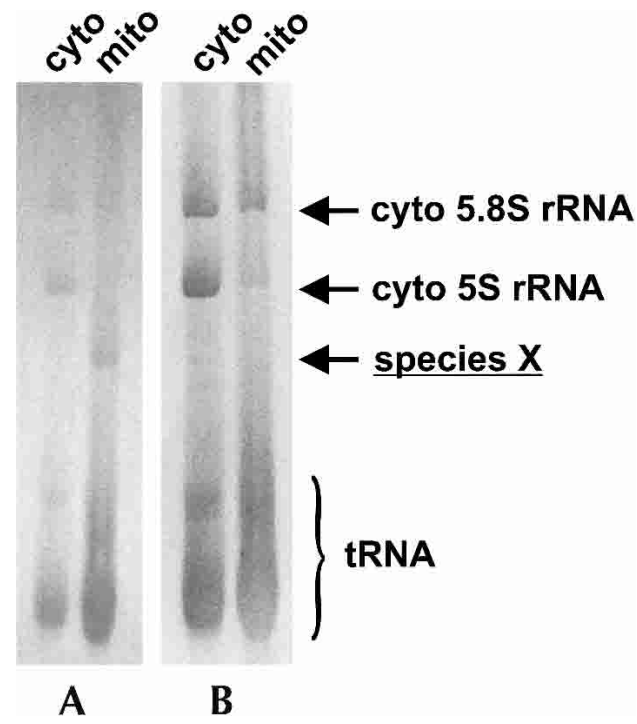

FIGURE 1. Visualization by $(A)$ UV shadowing and $(B)$ ethidium bromide staining of A. castellanii cytoplasmic (cyto) and mitochondrial (mito) RNAs separated on a $10 \%$ polyacrylamide gel. Note: The low-abundance RNA in the mitochondrial RNA preparation that comigrates with cytoplasmic 5.8S rRNA has a $3^{\prime}$-terminal sequence identical to that of cytoplasmic 5.8S rRNA (not shown). Our data indicate that this RNA has a single 3 '-terminal $U$ residue, whereas the number of $U$ residues is ambiguous in the published sequence (MacKay and Doolittle 1981).

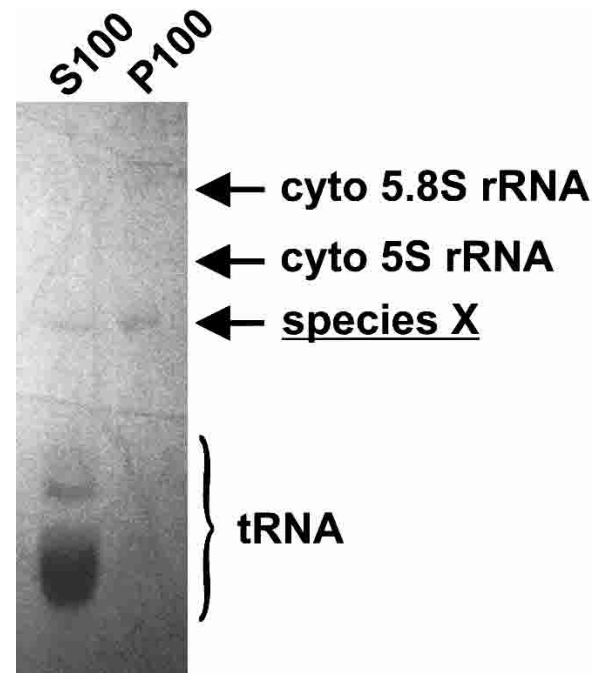

FIGURE 2. Visualization by UV shadowing of RNAs isolated from the supernatant (S100) and pellet (P100) of a 100,000g ultracentrifugation of a clarified Triton X-100 lysate of purified A. castellanii mitochondria. RNAs were separated on a $10 \%$ polyacrylamide gel. The positions of $A$. castellanii cytoplasmic (cyto) $5.8 \mathrm{~S}$ and $5 \mathrm{~S}$ rRNA markers are indicated.

was simplified by the unusually slow migration (relative to other 5S rRNAs) of A. castellanii cytoplasmic 5S rRNA (length $119 \mathrm{nt}$ ) under the gel electrophoresis conditions used.

The size and abundance of species $\mathrm{X}$ suggested that it could be a mitochondrial $5 \mathrm{~S}$ rRNA. To test this hypothesis, we investigated the mitochondrial localization of this RNA by subjecting a clarified Triton X-100 lysate of purified $A$. castellanii mitochondria to centrifugation at $100,000 \mathrm{~g}$ for $1.5 \mathrm{~h}$. We expected that if species X is a bona fide $5 \mathrm{~S}$ rRNA, it should remain associated with ribosomes and appear in the $100,000 \mathrm{~g}$ pellet under the conditions used in this study. RNA was prepared from both the supernatant (S100) and pellet (P100) fractions, and, as expected, a significant portion of species X was found in the P100 (Fig. 2). The species $\mathrm{X}$ present in the $\mathrm{S} 100$ might be due to incomplete sedimentation of mitochondrial ribosomes; alternatively, a low-molecular-weight ribonucleoprotein complex containing species X (a putative 5S rRNA) may have dissociated from a fraction of the ribosomes (see Moore 1996). Localization of tRNAs exclusively in the S100 confirms that the high-speed centrifugation did not pellet small RNA species that are not associated with large complexes. Together, these observations support the hypothesis that species $\mathrm{X}$ is associated with mitochondrial ribosomes.

To further characterize this novel ribosomal component, RNA sequence data were obtained. Both $3^{\prime}$-end-labeling (Fig. 3A) and 5'-end-labeling (Fig. 3C) of isolated species X resulted in four labeled RNA species (X1-X4), differing in length by $1 \mathrm{nt}$. By chemical sequencing of the $3^{\prime}$-end-labeled RNAs (Fig. 3B), the four RNAs were shown to have exactly the same $3^{\prime}$ termini, indicating that they must be 


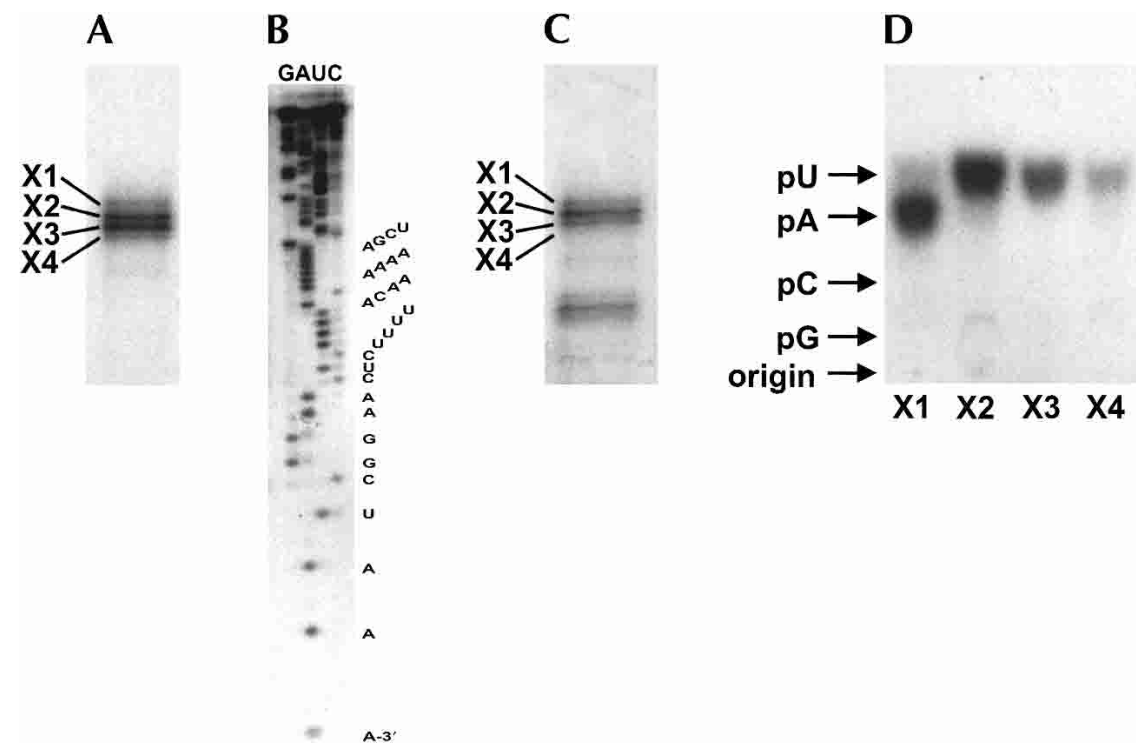

FIGURE 3. (A) Electrophoretic separation of $3^{\prime}$-end-labeled species $X$ and $(B)$ chemical sequencing of these labeled RNAs. A representative $20 \%$ polyacrylamide gel for RNA band X4 is displayed, with a portion of the deduced RNA sequence shown on the right. $(C)$ Electrophoretic separation of $5^{\prime}$-end-labeled species $\mathrm{X}$ and $(D)$ one-dimensional thin-layer chromatography of the products of P1 nuclease digestion of the four largest $5^{\prime}$-end-labeled RNAs (X1X4). The positions of nucleoside $5^{\prime}$-monophosphate markers are indicated. Autoradiograms are shown in all cases.

heterogeneous at their $5^{\prime}$ ends. Terminal analysis of $5^{\prime}$-endlabeled RNAs (Fig. 3D) revealed that the three shortest length variants (X2-X4, 116-118 nt) contained a U residue at their $5^{\prime}$ termini, whereas the longest variant (X1, $\left.119 \mathrm{nt}\right)$ had a $5^{\prime}$-terminal A. Because chemical sequencing gels of the $3^{\prime}$-end-labeled RNAs could be read to within a stretch of $\mathrm{U}$ residues near their $5^{\prime}$ ends, these combined analyses yielded RNA sequence data for every position in the molecule, demonstrating that species $\mathrm{X}$ is distinctly different in sequence from the nucleus-encoded cytoplasmic 5S rRNA of A. castellanii (MacKay and Doolittle 1981).

Alignment of the experimentally determined RNA sequence of species $\mathrm{X}$ with mitochondrial and eubacterial $5 \mathrm{~S}$ rRNA sequences (Fig. 4A) revealed nucleotide similarity within a region highly conserved in other $5 \mathrm{~S}$ rRNAs (outside of this stretch, very little primary structure conservation is evident among mitochondrial 5S rRNAs in general). In addition to displaying a diagnostic primary sequence motif, the RNA sequence of species $\mathrm{X}$ can be folded into a secondary structure (Fig. 4B) consistent with the consensus 5S rRNA secondary structure (Moore 1996). These data strongly suggest that species $\mathrm{X}$ is indeed a mitochondrial $5 \mathrm{~S}$ rRNA. The high A + U content of this 5 S rRNA (78\%) with concomitant relatively weak base pairing in stem regions presumably accounts for the failure of ethidium bromide to bind efficiently to this RNA species in gels.

A search of the complete mtDNA sequence of $A$. castellanii (Burger et al. 1995; GenBank accession number NC_001637) located the mitochondrial 5S rRNA gene (rrn5) within a previously unassigned 240-nt spacer between the cox $1 / 2$ and rps4 genes. The $5^{\prime}$ ends of this molecule map 109-112 nt downstream from the $3^{\prime}$ end of the coxl/2 reading frame, whereas the $3^{\prime}$ end maps $22 \mathrm{nt}$ upstream of the $5^{\prime}$ end of the rps 4 coding region. The $r r n 5$ gene is in the same transcriptional orientation as all other genes in this mitochondrial genome. When the A. castellanii mitochondrial 5S rRNA sequence was used as a query in BLAST searches of public domain databases, no other $5 \mathrm{~S}$ rRNA sequences (including any of the known mitochondrial ones) were detected.

\section{CONCLUSIONS}

Even though the A. castellanii mitochondrial 5S rRNA displays a degree of primary and secondary structure conservation clearly sufficient to mark it as a homolog of other $5 \mathrm{~S}$ rRNAs, extensive analysis of the complete mtDNA sequence (Burger et al. 1995) had previously failed to identify the corresponding gene. The 5S RNA species itself had also escaped detection over a number of years in experiments where ethidium bromide was routinely used to visualize gel-purified A. castellanii mitochondrial RNA species. The results reported here suggest that a $5 \mathrm{~S}$ rRNA species may be encoded in more mitochondrial genomes than is currently appreciated. Clearly, direct characterization of mitochondrial RNAs by several methods remains the most reliable approach to identifying mitochondrial $5 S$ rRNAs and their genes.

In this regard, it is noteworthy that even with the $A$. castellanii mitochondrial 5S rRNA sequence in hand, we are not able to identify a homologous sequence in the mitochondrial genome of Dictyostelium discoideum (Ogawa et al. 2000), a member of the same protist phylum (Amoebozoa) to which A. castellanii belongs (Cavalier-Smith 1998). The $A$. castellanii and $D$. discoideum mitochondrial genomes share a number of features in common, including an almost identical gene content, a single open reading frame (coxl/ cox2) encoding subunits 1 and 2 of cytochrome oxidase, and a similar set of tRNA genes whose transcripts require the same type of $5^{\prime}$ editing (Burger et al. 1995; Ogawa et al. 2000). D. discoideum mtDNA does encode a 129-nt RNA species ( $\mathrm{Pi}$ et al. 1998) that, however, lacks the diagnostic primary and secondary structural features of a conventional $5 \mathrm{~S}$ rRNA, and which displays no convincing sequence similarity to the A. castellanii mitochondrial 5S rRNA sequence described here. The fact that this novel RNA component does not appear to be associated with $D$. discoideum mito- 
A
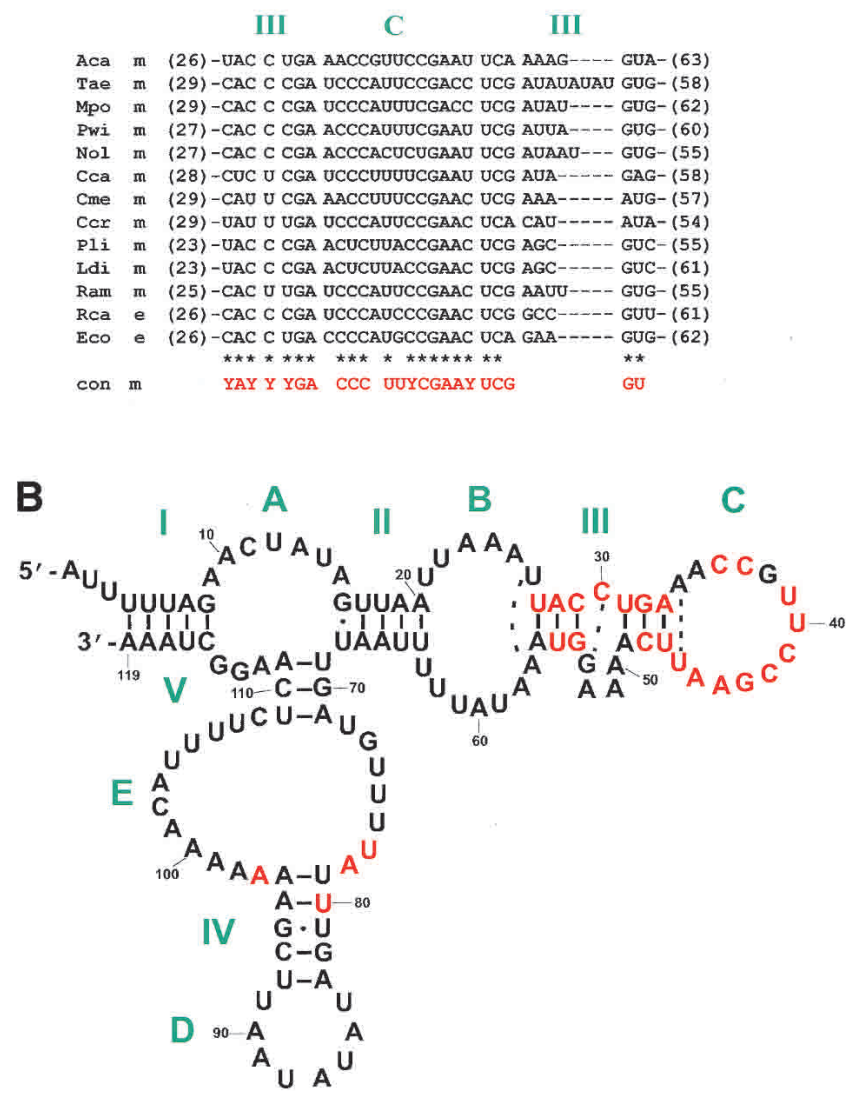

FIGURE 4. (A) Alignment of a conserved portion of mitochondrial (m) and eubacterial (e) 5S rRNA sequences. Sequences used (GenBank accession number in parentheses): Acanthamoeba castellanii (Aca; this work), Triticum aestivicum (Tae; M10361), Marchantia polymorpha (Mpo; M68929), Prototheca wickerhamii (Pwi; U02970), Nephroselmis olivacea (Nol; AF110138), Cyanidium caldarium (Cca; Z48930), Cyanidioschyzon merolae (Cme; D89861), Chondrus crispus (Ccr; Z47547), Pylaiella littoralis (Pli; AJ277126), Laminaria digitata (Ldi; AJ344328), Reclinomonas americana (Ram; U59762), Rhodobacter capsulata (Rca; X04585), and Escherichia coli (Eco; X00414). The spacing in the alignment represents the alternation of single- and doublestranded regions. Dashes (-) indicate alignment gaps. Numbers in parentheses indicate nucleotides not shown. The consensus (con $\mathrm{m}$ ) indicates positions that are either identical in at least 9 of the 11 mitochondrial sequences or of the same type $(\mathrm{Y}=$ pyrimidine, $\mathrm{R}=$ purine) in all 11 mitochondrial sequences. Asterisks indicate positions in the mitochondrial consensus that are also conserved in the eubacterial sequences. $(B)$ Potential RNA secondary structure of the longest sequence variant of the A. castellanii mitochondrial 5S rRNA. Red indicates nucleotides identical to the mitochondrial consensus. Additional potential base-pairing is indicated by broken lines. Helices I to $\mathrm{V}$ and loops A to E are denoted as in Burger et al. (1999).

chondrial ribosomes (Pi et al. 1998) argues against the possibility that it is a nonhomologous but functional equivalent of a conventional $5 S$ rRNA. If $D$. discoideum mitochondrial ribosomes do in fact lack the equivalent of a $5 \mathrm{~S}$ rRNA component (mtDNA-encoded or otherwise), this disparity between two otherwise very similar amoebozoan mitochondrial systems would strengthen the view that the mitochon- drial translation system is unusually flexible in its requirement for a $5 \mathrm{~S}$ rRNA component.

\section{MATERIALS AND METHODS}

\section{Isolation of mitochondrial and cytoplasmic RNA}

A. castellanii strain Neff (ATCC 30010 ) was grown at $30^{\circ} \mathrm{C}$ with moderate shaking to an O.D. ${ }_{550}$ of $\sim 1.0$. Mitochondria were purified (Price and Gray 1999) and cytoplasmic and mitochondrial RNAs were isolated as described (Spencer et al. 1992). RNAs were separated on a $1.5-\mathrm{mm}$-thick $10 \%$ polyacrylamide gel (all polyacrylamide gels used in this study contained $7 \mathrm{M}$ urea; Spencer et al. 1992) and eluted from a homogenized gel slice by shaking overnight at $4^{\circ} \mathrm{C}$ in a $1: 1$ mixture of phenol-cresol:buffer $[0.5 \mathrm{M}$ $\mathrm{NH}_{4} \mathrm{OAc}, 10 \mathrm{mM} \mathrm{Mg}(\mathrm{OAc})_{2}, 1.0 \mathrm{mM}$ EDTA]. RNAs were precipitated twice with ethanol, redissolved in water, and stored at $-20^{\circ} \mathrm{C}$ in $50 \%$ ethanol.

\section{Fractionation of mitochondria}

Purified mitochondria were gently lysed in a solution containing 2\% Triton X-100, $10 \mathrm{mM}$ Tris- $\mathrm{HCl}$ ( $\mathrm{pH} 8.5$ ), $50 \mathrm{mM} \mathrm{KCl}$, and 10 $\mathrm{mM} \mathrm{MgCl}_{2}$ (Spencer et al. 1992) and centrifuged at 9,000g in a fixed-angle rotor for $10 \mathrm{~min}$. The clarified supernatant was further fractionated by ultracentrifugation at $100,000 \mathrm{~g}$ for $1.5 \mathrm{~h}$ in a fixedangle rotor. RNAs were separated on a $1.5-\mathrm{mm}$-thick $10 \%$ polyacrylamide gel and visualized by UV shadowing (Hassur and Whitlock 1974).

\section{Chemical sequencing of RNA}

RNAs were $3^{\prime}$-end-labeled with $\left[5^{\prime}-{ }^{32} \mathrm{P}\right] \mathrm{pCp}$ and RNA ligase (Peattie 1979) and purified on a $6 \%$ polyacrylamide sequencing gel. Chemical sequencing reactions were performed as described (Peattie 1979), and products were resolved in $6 \%$ and $20 \%$ polyacrylamide gels.

\section{5'-End analysis of RNA}

RNAs were $5^{\prime}$-end labeled with $\left[\gamma-{ }^{32} \mathrm{P}\right]$ ATP and polynucleotide kinase (Schnare et al. 1985) and purified as for the products of 3 '-end-labeling. Labeled products were excised and extracted from the gel and treated with P1 nuclease, which generates nucleoside 5' monophosphates $(\mathrm{pN})$. The products of $\mathrm{P} 1$ digestion were separated by one-dimensional thin-layer chromatography using cellulose plates (predipped in a $10 \%$ dilution of a saturated solution of $\mathrm{NH}_{4} \mathrm{SO}_{4}$ ) and a 4:1 mixture of $95 \%$ ethanol:water as the solvent (Lane 1963).

\section{ACKNOWLEDGMENTS}

This research was supported by a research grant from the Canadian Institutes of Health Research (MOP-4124) to M.W.G. and a fellowship from the Walter C. Sumner Foundation to C.E.B. Salary and interaction support from the Canadian Institute for Advanced 
Research and the Canada Research Chairs Program to M.W.G. is gratefully acknowledged.

The publication costs of this article were defrayed in part by payment of page charges. This article must therefore be hereby marked "advertisement" in accordance with 18 USC section 1734 solely to indicate this fact.

Received November 1, 2002; accepted November 25, 2002.

\section{REFERENCES}

Bonen, L. and Gray, M.W. 1980. Organization and expression of the mitochondrial genome of plants I. The genes for wheat mitochondrial ribosomal and transfer RNA: Evidence for an unusual arrangement. Nucleic Acids Res. 8: 319-335.

Burger, G., Plante, I., Lonergan, K.M., and Gray, M.W. 1995. The mitochondrial DNA of the amoeboid protozoon, Acanthamoeba castellanii: Complete sequence, genome content and genome organization. J. Mol. Biol. 245: 522-537.

Burger, G., Saint-Louis, D., Gray, M.W., and Lang, B.F. 1999. Complete sequence of the mitochondrial DNA of the red alga Porphyra purpurea. Cyanobacterial introns and shared ancestry of red and green algae. Plant Cell 11: 1675-1694.

Cavalier-Smith, T. 1998. A revised six-kingdom system of life. Biol. Rev. Camb. Philos. Soc. 73: 203-266.

Cunningham, R.S., Bonen, L., Doolittle, W.F., and Gray, M.W. 1976. Unique species of $5 \mathrm{~S} 18 \mathrm{~S}$ and $26 \mathrm{~S}$ ribosomal RNA in wheat mitochondria. FEBS Lett. 69: 116-122.

Datema, R., Agsteribbe, E., and Kroon, A.M. 1974. The mitochondrial ribosomes of Neurospora crassa. I. On the occurrence of 80-S ribosomes. Biochim. Biophys. Acta 335: 386-395.

Entelis, N.S., Kolesnikova, O.A., Dogan, S., Martin, R.P., and Tarassov, I.A. 2001. $5 \mathrm{~S}$ rRNA and tRNA import into human mitochondria. Comparison of in vitro requirements. J. Biol. Chem. 276: 4564245653.

Gray, M.W., Lang, B.F., Cedergren, R., Golding, G.B., Lemieux, C., Sankoff, D., Turmel, M., Brossard, N., Delage, E., Littlejohn, T.G., et al. 1998. Genome structure and gene content in protist mitochondrial DNAs. Nucleic Acids Res. 26: 865-878.

Gutell, R.R., Gray, M.W., and Schnare, M.N. 1993. A compilation of large subunit (23S and 23S-like) ribosomal RNA structures: 1993. Nucleic Acids Res. 21: 3055-3074.

Hassur, S.M. and Whitlock Jr., H.W. 1974. UV shadowing-A new and convenient method for the location of ultraviolet-absorbing species in polyacrylamide gels. Anal. Biochem. 59: 162-164.

Kubo, T., Nishizawa, S., Sugawara, A., Itchoda, N., Estiati, A., and Mikami, T. 2000. The complete nucleotide sequence of the mitochondrial genome of sugar beet (Beta vulgaris L.) reveals a novel gene for tRNA ${ }^{\text {Cys }}$ (GCA). Nucleic Acids Res. 28: 2571-2576.

Lane, B.G. 1963. The separation of adenosine, guanosine, cytidine and uridine by one-dimensional filter-paper chromatography. Biochim. Biophys. Acta 72: 110-112.

Lang, B.F., Cedergren, R., and Gray, M.W. 1987. The mitochondrial genome of the fission yeast, Schizosaccharomyces pombe. Sequence of the large-subunit ribosomal RNA gene, comparison of potential secondary structure in fungal mitochondrial large-subunit rRNAs and evolutionary considerations. Eur. J. Biochem. 169: 527-537.

Lang, B.F., Goff, L.J., and Gray, M.W. 1996. A 5 S rRNA gene is present in the mitochondrial genome of the protist Reclinomonas americana but is absent from red algal mitochondrial DNA. J. Mol. Biol. 261: 407-413.

Lang, B.F., Gray, M.W., and Burger, G. 1999. Mitochondrial genome evolution and the origin of eukaryotes. Annu. Rev. Genet. 33: 351397.

Leaver, C.J. and Harmey, M.A. 1976. Higher-plant mitochondrial ribosomes contain a $5 \mathrm{~S}$ ribosomal ribonucleic acid component. Biochem. J. 157: 275-277.
Lizardi, P.M. and Luck, D.J. 1971. Absence of a 5S RNA component in the mitochondrial ribosomes of Neurospora crassa. Nat. New Biol. 229: $140-142$.

MacKay, R.M. and Doolittle, W.F. 1981. Nucleotide sequences of Acanthamoeba castellanii $5 \mathrm{~S}$ and $5.8 \mathrm{~S}$ ribosomal ribonucleic acids: Phylogenetic and comparative structural analyses. Nucleic Acids Res. 9: 3321-3334.

Magalhães, P.J., Andreu, A.L., and Schon, E.A. 1998. Evidence for the presence of $5 \mathrm{~S}$ rRNA in mammalian mitochondria. Mol. Biol. Cell 9: 2375-2382.

Michel, R., Hallermayer, G., Harmey, M.A., Miller F., and Neupert, W. 1977. The $73 \mathrm{~S}$ ribosome of Neurospora crassa is the native mitochondrial ribosome. Biochim. Biophys. Acta 478: 316-330.

Moore, P.B. 1996. The structure and function of $5 \mathrm{~S}$ ribosomal RNA. In Ribosomal RNA: Structure, evolution, processing and function in protein biosynthesis (eds. R.A. Zimmermann and A.E. Dahlberg), pp. 199-236, CRC Press, Boca Raton, FL.

Nierlich, D.P. 1982. Fragmentary 5S rRNA gene in the human mitochondrial genome. Mol. Cell. Biol. 2: 207-209.

O'Brien, T.W. and Denslow, N.D. 1996. Bovine mitochondrial ribosomes. Methods Enzymol. 264: 237-248.

Oda, K., Yamato, K., Ohta, E., Nakamura, Y., Takemura, M., Nozato, N., Akashi, K., Kanegae, T., Ogura, Y., Kohchi, T., et al. 1992. Gene organization deduced from the complete sequence of liverwort Marchantia polymorpha mitochondrial DNA. A primitive form of plant mitochondrial genome. J. Mol. Biol. 223: 1-7.

Ogawa, S., Yoshino, R., Angata, K., Iwamoto, M., Pi, M., Kuroe, K., Matsuo, K., Morio, T., Urushihara, H., Yanagisawa, K., et al. 2000. The mitochondrial DNA of Dictyostelium discoideum: Complete sequence, gene content and genome organization. Mol. Gen. Genet. 263: 514-519.

Ohta, N., Sato, N., and Kuroiwa, T. 1998. Structure and organization of the mitochondrial genome of the unicellular red alga Cyanidioschyzon merolae deduced from the complete nucleotide sequence. Nucleic Acids Res. 26: 5190-5198.

Oudot-Le Secq, M.-P., Fontaine, J.-M., Rousvoal, S., Kloareg, B., and Loiseaux-de-Goër, S. 2001. The complete sequence of a brown algal mitochondrial genome, the ectocarpale Pylaiella littoralis (L.) Kjellm. J. Mol. Evol. 53: 80-88.

Oudot-Le Secq, M.-P., Kloareg, B., and Loiseaux-de-Goër, S. 2002. The mitochondrial genome of the brown alga Laminaria digitata: A comparative analysis. Eur. J. Phycol. 37: 163-172.

Peattie, D.A. 1979. Direct chemical method for sequencing RNA. Proc. Natl. Acad. Sci. 76: 1760-1764.

Pi, M., Morio, T., Urushihara, H., and Tanaka, Y. 1998. Characterization of a novel small RNA encoded by Dictyostelium discoideum mitochondrial DNA. Mol. Gen. Genet. 257: 124-131.

Price, D.H. and Gray, M.W. 1999. A novel nucleotide incorporation activity implicated in the editing of mitochondrial transfer RNAs in Acanthamoeba castellanii. RNA 5: 302-317.

Rosset, R. and Monier, R. 1963. A propos de la présence d'acide ribosomique de faible poids moléculaire. Bull. Soc. Chim. Biol. 46: 87-109.

Schnare, M.N., Heinonen, T.Y.K., Young, P.G., and Gray, M.W. 1985. Phenylalanine and tyrosine transfer RNAs encoded by Tetrahymena pyriformis mitochondrial DNA: Primary sequence, post-transcriptional modifications and gene localization. Curr. Genet. 9: 389-393.

Spencer, D.F., Bonen, L., and Gray, M.W. 1981. Primary sequence of wheat mitochondrial $5 \mathrm{~S}$ ribosomal ribonucleic acid: Functional and evolutionary implications. Biochemistry 20: 4022-4029.

Spencer, D.F., Schnare, M.N., and Gray, M.W. 1992. Isolation of wheat mitochondrial DNA and RNA. In Modern methods of plant analysis vol. 4: Seed analysis (eds. H.F. Linskens and J.F. Jackson), pp. 347-360. Springer-Verlag, Berlin.

Thurlow, D.L., Mason, T.L., and Zimmermann, R.A. 1984. 5 S RNAlike structures in large ribosomal subunit RNAs of fungal mitochondria. FEBS Lett. 173: 277-282.

Turmel, M., Lemieux, C., Burger, G., Lang, B.F., Otis, C., Plante, I., 


\section{Bullerwell et al.}

and Gray, M.W. 1999. The complete mitochondrial DNA sequences of Nephroselmis olivacea and Pedinomonas minor. Two radically different evolutionary patterns within green algae. Plant Cell 11: 1717-1730.

Turmel, M., Otis, C., and Lemieux, C. 2002a. The complete mitochondrial DNA sequence of Mesostigma viride identifies this green alga as the earliest green plant divergence and predicts a highly compact mitochondrial genome in the ancestor of all green plants. Mol. Biol. Evol. 19, 24-38.

2002b. The chloroplast and mitochondrial genome sequences of the charophyte Chaetosphaeridium globosum: Insights into the timing of the events that restructured organelle DNAs within the green algal lineage that led to land plants. Proc. Natl. Acad. Sci. 99: $11275-11280$.

Unseld, M., Marienfeld, J.R., Brandt, P., and Brennicke, A. 1997. The mitochondrial genome of Arabidopsis thaliana contains 57 genes in 366,924 nucleotides. Nat. Genet. 15: 57-61.

Wolff, G., Plante, I., Lang, B.F., Kück, U., and Burger, G. 1994. Complete sequence of the mitochondrial DNA of the chlorophyte alga Prototheca wickerhamii. Gene content and genome organization. J. Mol. Biol. 237: 75-86.

Yoshionari, S., Koike, T., Yokogawa, T., Nishikawa, K., Ueda, T., Miura, K., and Watanabe, K. 1994. Existence of nuclear-encoded 5S-rRNA in bovine mitochondria. FEBS Lett. 338: 137-142. 

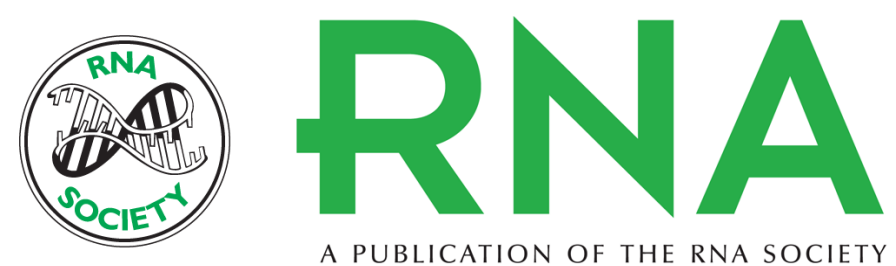

A PUBLICATION OF THE RNA SOCIETY

\section{Discovery and characterization of Acanthamoeba castellanii mitochondrial 5S rRNA}

CHARLES E. BULLERWELL, MURRAY N. SCHNARE and MICHAEL W. GRAY

RNA 2003 9: 287-292

References This article cites 37 articles, 8 of which can be accessed free at: http://rnajournal.cshlp.org/content/9/3/287.full.html\#ref-list-1

\section{License}

Email Alerting Receive free email alerts when new articles cite this article - sign up in the box at the Service top right corner of the article or click here. 